\title{
DEVELOPMENT OF CONTROL SYSTEM OF HOT WATER SUPPLY SOLAR PLANT
}

\author{
Alexandr V. Belousov \\ Institute of Power Engineering, Information Technologies \\ and Operating Systems \\ Dept. of Electrical Engineering and Automation \\ Belgorod State Technological University \\ named after V. G. Shukhov \\ Belgorod, Russian Federation \\ ntk.intbel.ru
}

\author{
Yury A. Koshlich \\ Institute of Power Engineering, Information Technologies \\ and Operating Systems \\ Dept. of Electrical Engineering and Automation \\ Belgorod State Technological University \\ named after V. G. Shukhov \\ Belgorod, Russian Federation \\ koshlich@yandex.ru
}

\author{
Vasily K. Stan \\ Institute of Power Engineering, Information Technologies \\ and Operating Systems \\ Dept. of Electrical Engineering and Automation \\ Belgorod State Technological University \\ named after V. G. Shukhov \\ Belgorod, Russian Federation \\ madseal@yandex.ru
}

\begin{abstract}
This article is devoted to the development of technical solutions and structures aimed at improving energy efficiency of solar plants in the regions with temperate continental climate through the adaptive control of coolant velocity. The main development stages of the adaptive control system and its operating features are considered in the article. To determine the optimal settings of the coolant loop controllers and the hot water loop, mathematical identification of the solar plant was made. Basing on different values of external factors (ambient temperature, insolation) and coolant velocity, static characteristics of the solar plant of extreme nature were obtained. The transient response analysis was used to obtain the dynamic solar model. On the basis of the developed models an adaptive step-by-step algorithm for controlling heat exchange process was created. Data on the state of the plant received from the sensors were also used. An adaptive automatic control system for solar plant of hot water supply was developed. Its application makes it possible to increase energy efficiency of hot water supply due to the increase in the amount of accumulated thermal energy at low control costs. Indirect compensation of external influences would be a distinctive feature of the method, which allows improving the quality of control processes.
\end{abstract}

Keywords-solar plant; energy efficiency; variable-frequency electric drive; adaptive control.

\section{INTRODUCTION}

Rapid technological progress development inevitably entails an increase of the energy consumption. That is why great attention is paid to the issues of energy supply to buildings. One of the ways to solve this problem is to use the alternative energy sources and, in particular, water-heating solar plants widely used in various fields of human activity: industry, agriculture and the sector of housing and utilities. Solar plants are not widely used in the Russian Federation because of the low level of solar radiation and a small number of sunny days, which significantly reduces their profitability [1]. In addition, for a solar plant to be operated in a temperate continental climate, it is necessary to ensure its resistance to low temperatures [2].

To solve this problem, an analysis of solar plant constructions was carried out among which there are as follows: systems with natural coolant circulation, active twocircuit systems with an external heat exchanger and active two-circuit systems with an additional energy source (AES) [3].

Systems with natural circulation are the simplest among those which were considered: they consist only of a solar collector and a heat accumulator (Fig. 1).

This system is fixed and the efficiency of its operation depends directly on the external conditions, and, consequently, its application in the conditions of moderate climate is impractical [4]. 


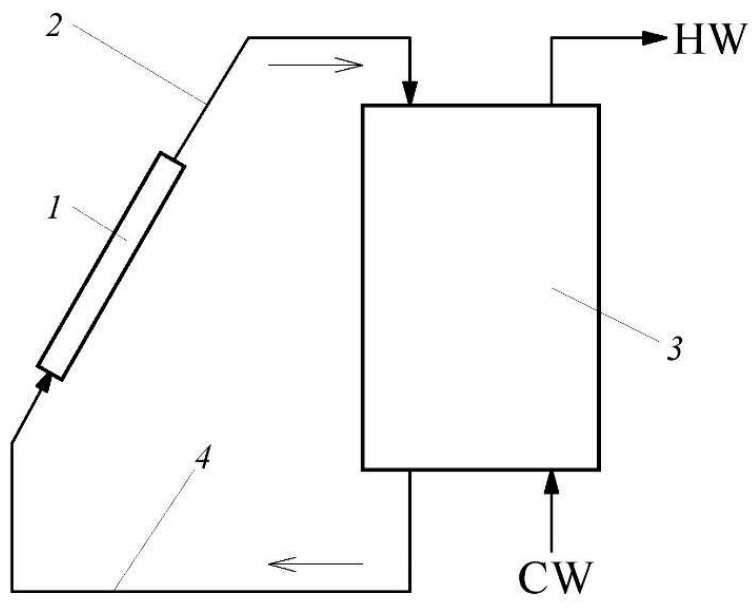

Fig. 1. Operating diagram of thermal solar plant with natural circulation of coolant: 1 - solar plate, 2 - discharge pipe, 3 - thermal energy storage tank, 4 - cold water charging pipe, CW - cold water, $\mathrm{HW}$ - hot water

Active two-circuit systems with an external heat exchanger differ from the previous systems [5]. First of all, the use of a two-circuit system allows to protect the external loop of the system from its defrosting using liquids with a low freezing point (antifreeze) as the coolant. Secondly, the force-feed circulation of the low-temperature coolant makes it possible to eliminate the stagnation of the coolant in the collector, as well as its overheating. Thirdly, the use of a controlled valve with a heat controller allows adjusting water temperature at the output from the system down from the value of water temperature in the tank [6].



Fig. 2. Operating diagram of active two-circuit systems with an external heat exchanger: 1 - solar panel, 2 - discharge pipe, 3 - thermal energy storage tank, 4 - cold water charging pipe, 5 - recycling pump, 6 - thermostatic mixing valve, 7 - heat exchanger, $\mathrm{CW}$ - cold water, $\mathrm{HW}$ - hot water

Thus, these systems solve the issue of operation in a temperate climate but they are not sufficiently effective, since the pump is controlled with the help of a two-position regulator.

Two-circuit solar plants with an additional energy source are the versions of the previous type of the systems (Fig. 3) [7].

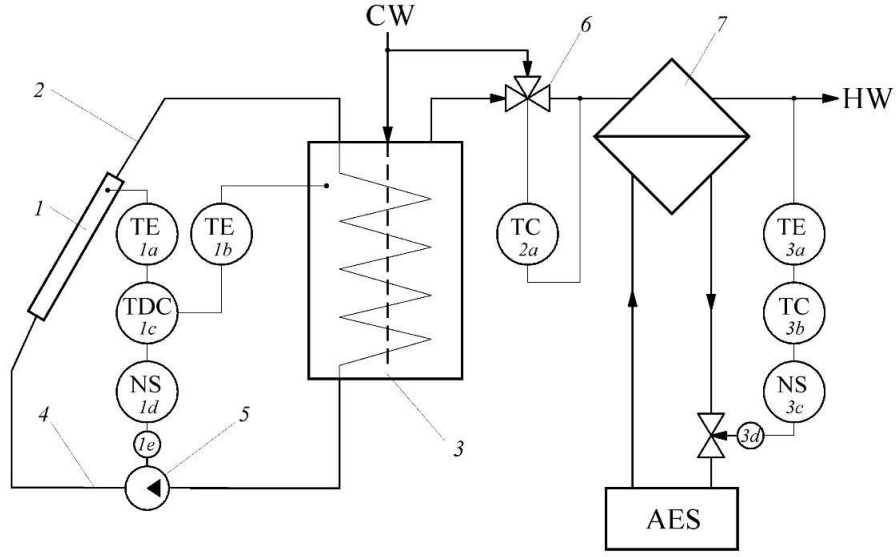

Fig. 3. Operating diagram of active two-circuit systems with a heat exchanger and accumulator and supplementary energy source (AES). 1 - solar plate, 2 - discharge pipe, 3 - thermal energy storage tank, 4 - cold water charging pipe, 5 - recycling pump, 6 - thermostatic mixing valve, 7 - heat exchanger, CW - cold water, HW - cold water, AES - additional energy source.

In addition to the defrosting protection, plants of this type have ability to heat water at the output to the required temperature because of the additional power source. Besides, the issue of high cost of external heat exchangers was solved. Now a combined storage tank (a coil built in the tank is used as a heat exchanger) is used.

However, the control of the heat transfer process from the low-temperature coolant to the water in the storage tank is also carried out by a two-position heat controller, which significantly reduces the efficiency of this process and of the solar plant as a whole. Thus, ensuring the operation of a water heating plant in a temperate zone climate the most important issue remains to be unsolved, i.e. operation of the plant from energy efficiency point of view [8].

\section{MAIN PART}

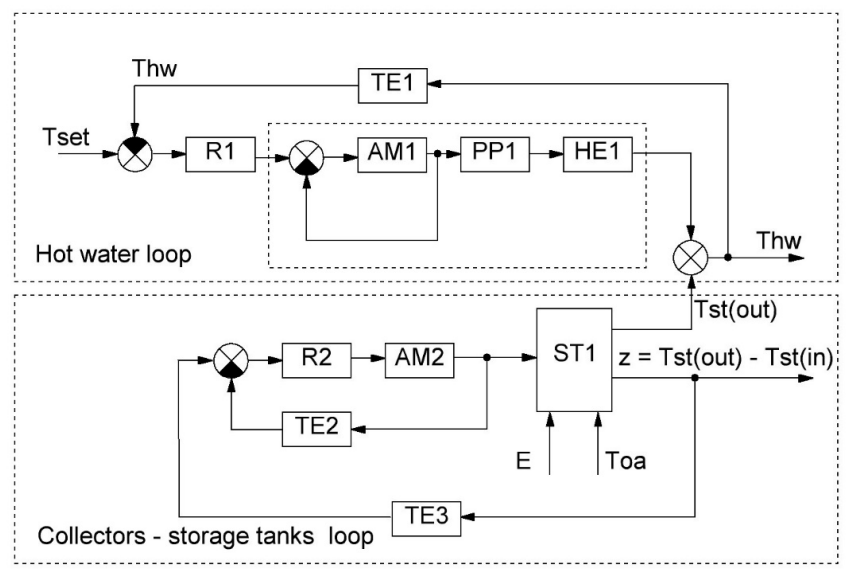

Fig. 4. General diagram of initial ACS. TE1 - output GBS temperature sensor, R1 -GBS controller, AM1 - actuator (valve drive), PP1 - control valve, HE1 - heat exchanger, R2 - loop controller SK - BA, AM2 - actuator (pump), ST1 - storage tank of solar plant, E - insolation, Toa - outside temperature, $\mathrm{z}$ - difference of coolant temperatures: inlet and outlet of BA. 
To solve this problem, an active-type solar plant with AES (Fig. 3) was used. The plant was equipped with two control loops: a heat exchange loop between the collectors and the thermal accumulator (hereinafter: SK - BA loop) and a control loop for the outlet water temperature system (hereinafter: GBS loop). Two-position heat controllers were used to control the system. (Fig. 4).

Due to previously accumulated data describing the solar plant operation, the studying process of the solar plant did not take long. The analysis of the accumulated statistical data made it possible to reveal the connection between the circulation velocity of the coolant in the collector and the efficiency of heat exchange process with the storage tank (Fig. 5) [1]. It shows that the dependence is non-linear and the value of the extremum of the function depends on the temperature of outside air, insolation, and many other external factors that are difficult to take into account when designing the plant control system [9].

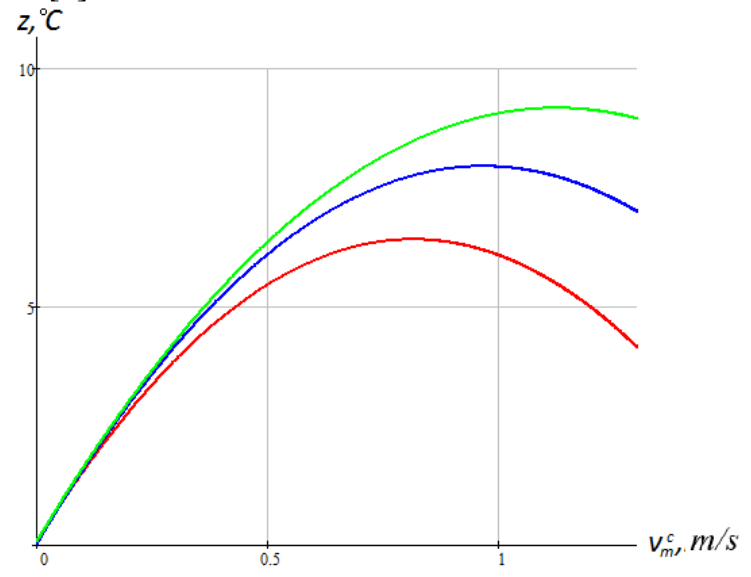

Fig. 5. Static characteristic of solar plant

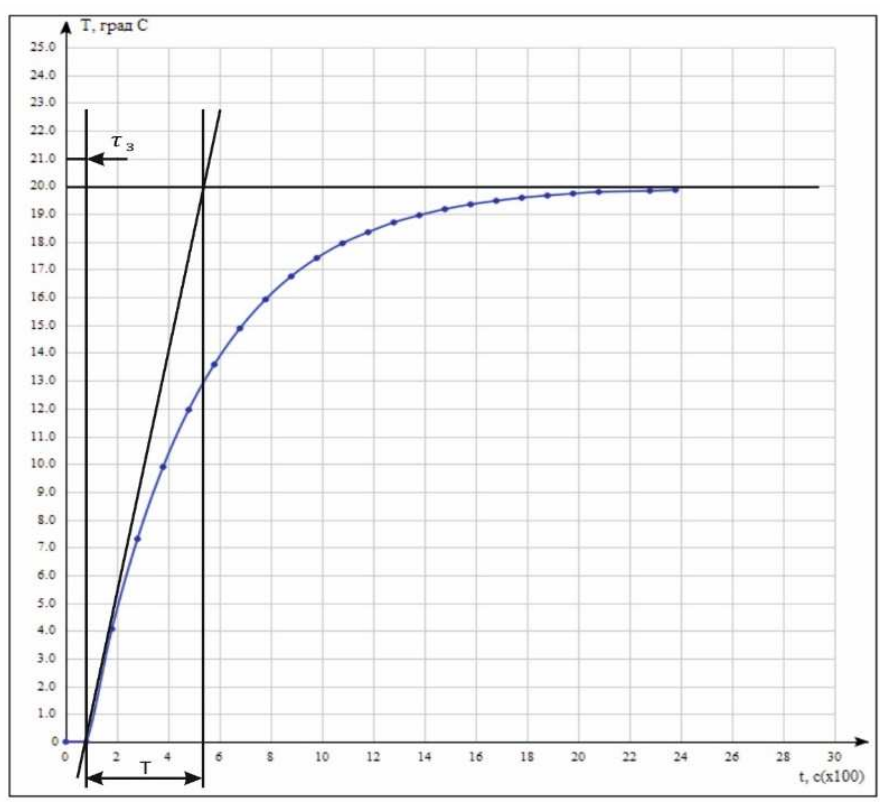

Fig. 6. Acceleration curve of heat exchange loop between solar collectors and heat accumulator
To design controllers with high control quality indicators, a mathematical identification of the solar plant as a heat engineering control unit was made. A method for obtaining acceleration curves was chosen as a method of investigation, which allows determining the parameters of the studied system. As a result of the experiment, the acceleration curves were obtained for both the BA-SK loop (Fig. 6) and GBS loop (Fig. 7).

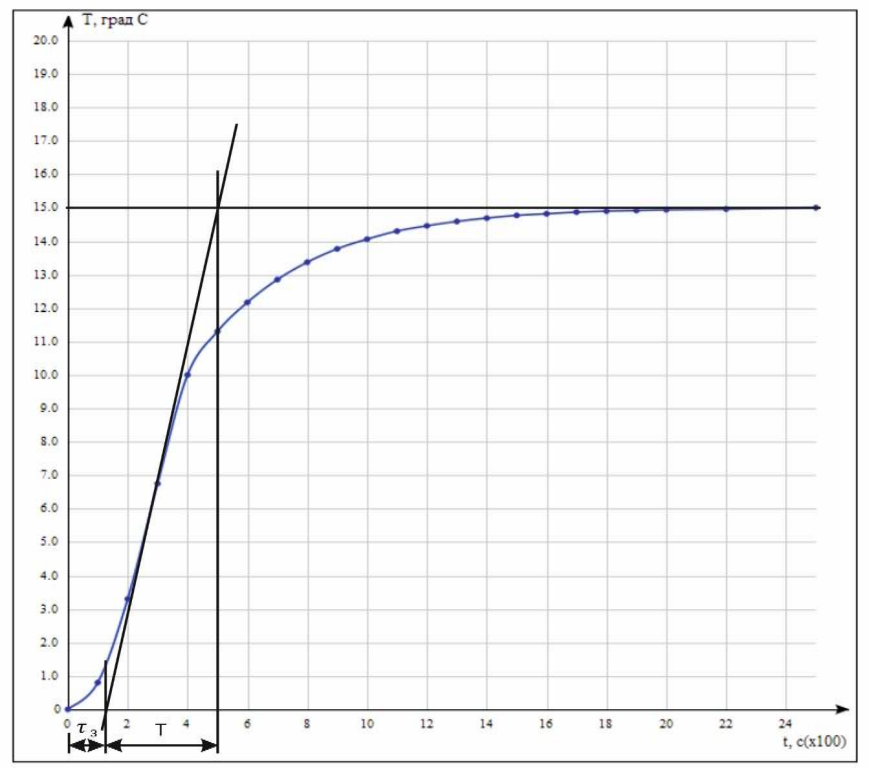

Fig. 7. Acceleration curve of water temperature control loop (system output)

Basing on the received data, the selection and adjustment of controllers was accomplished. For the water temperature control loop (system output), as for a stationary system with aperiodic transient response, according to Kopelovich method, PI temperature controller $(\mathrm{P}=5.4, \mathrm{I}=0.001459)$ was selected and adjusted [10]. For the heat exchange loop in the storage tank, since the environmental parameters are not constant but directly affect the operation of the solar plant, it was decided to use the adaptive step-be-step controller [11].

Assuming that the temperature difference at its input and output $\mathrm{z}$ is a qualitative indicator of heat exchange efficiency in the storage tank, let us take the increment of this value for the increment of the optimized function [12]:

$$
I=z \rightarrow \max
$$

Thus, one can create the following conditions for the controller to be transferred to a position different from the current one:

1. To increase the intensity of heat exchange in the internal storage tank, it is necessary for the temperature difference at its outlet and inlet to be positive and be higher than the temperature difference at the previous comparison point. Thus, the frequency of the voltage will increase, and the function will tend to its maximum value, i.e.: 


$$
\left[\text { delta } z>0 \rightarrow f_{i}=f_{i-1}+[\text { delta }] f\right.
$$

where $[$ delta $] f$ is a frequency step.

2. If a derivative sign is changed from positive to negative one, the function passes through the maximum point to a decay zone, which means that a decrease in the intensity of heat exchange is needed so that the temperature difference at the tank output and input becomes negative (stop the discharge of the tank), i.e. :

$$
[\text { delta }] z>0 \rightarrow f_{i}=f_{i-1}-[\text { delta }] f .
$$

3. In case there is no change in the temperature difference at the input and output, full charging of the thermal battery or the optimum operation of the pump is observed; hence, the intensity of heat exchange must be kept unchanged, i.e.:

$$
[\text { delta }] z>0 \rightarrow f_{i}=f_{i-1} \text {. }
$$

The system performs the comparison operations within the time equal to the time constant obtained from the acceleration characteristic, which allows performing more qualitative assessment of heat exchange process and reduces the cost of control [10].

Based on the analysis and synthesis of the controller, a control system was developed, the structure of which is shown in Fig. 8.

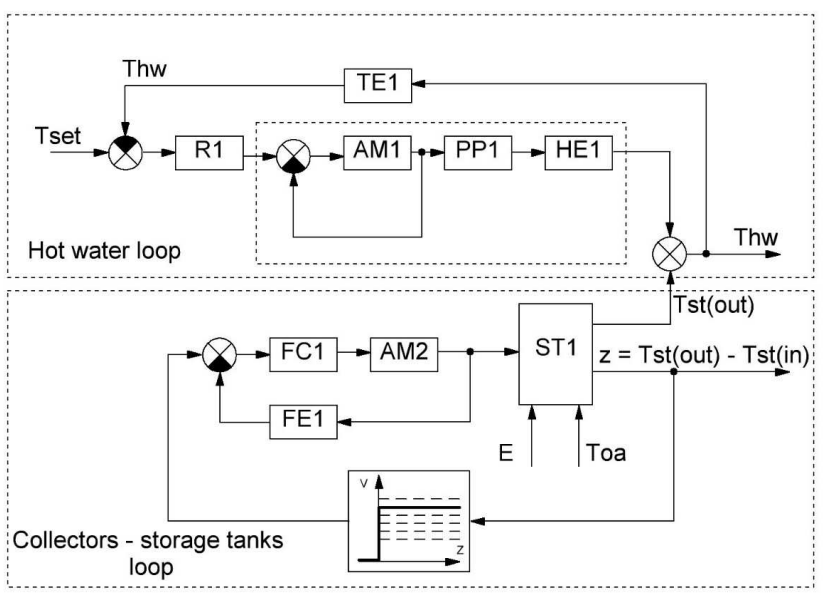

Fig. 8. General ACS diagram. TE1 - output GBS temperature sensor, R1 GBS

- actuator (valve drive)

HE1 - heat exchanger, FC1 - frequency converter, AM2 - actuator (pump), ST1 - storage tank of solar plant, FE1 - internal coolant flow sensor, E insolation, Toa - outside temperature, $\mathrm{z}$-difference of coolant temperatures: inlet and outlet of BA.

In order to assess the efficiency of the developed method of control, the solar plant for hot water supply system was remodeled. For the control system to operate in a proper manner, there is a program for the controller, which implements previously developed control algorithms; all necessary equipment was selected and installed; the program was integrated into the centralized control system of power complex of facility, which allowed one to monitor the process of installation remotely and effectively collect data for subsequent analysis (Fig. 9) [4]. To implement step-by-step adaptive control mechanism, a frequency-controlled electric drive of the recycling pump was used.

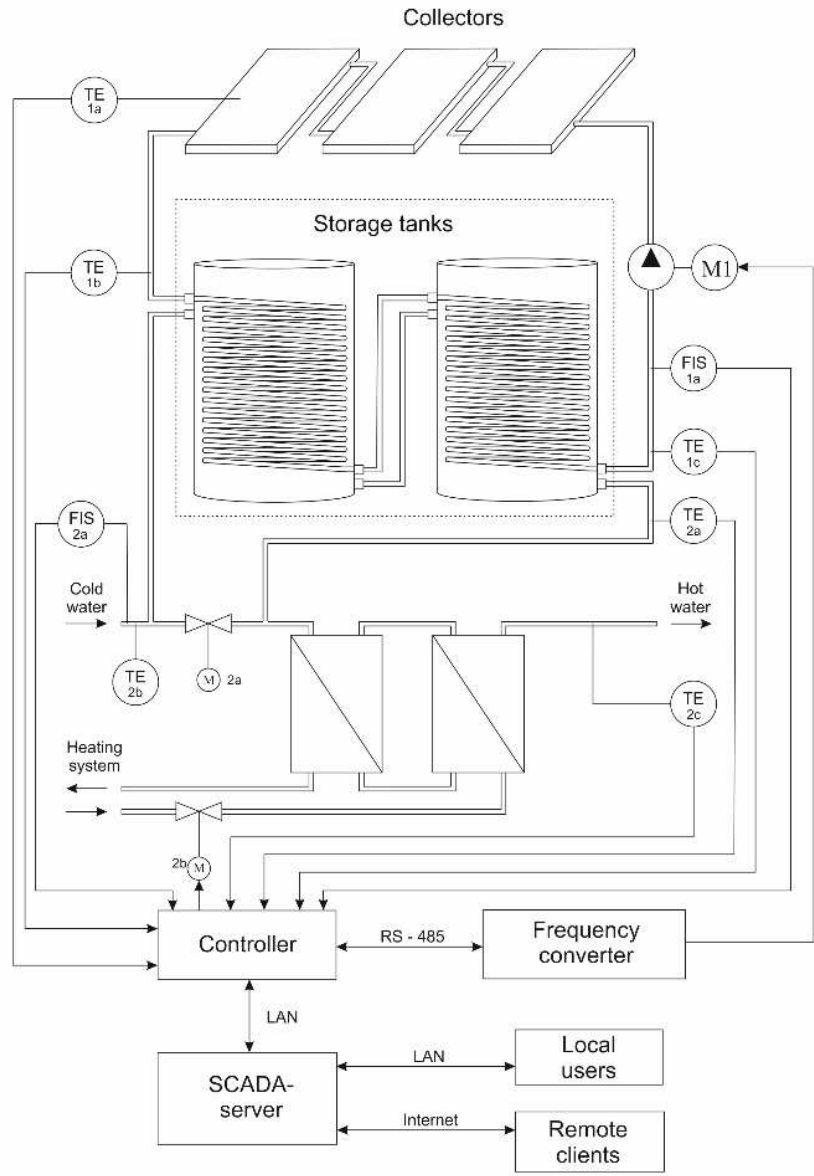

Fig. 9. Operating diagram.

\section{OUTCOMES}

After the developed solar control system has been implemented, a comparative data analysis of system operation and operation of the system using two-position control of the heat exchange process was carried out. As a result, it was concluded that the developed control algorithm allows increasing heat output produced by the plant, thereby increasing its energy efficiency (Fig. 10). 


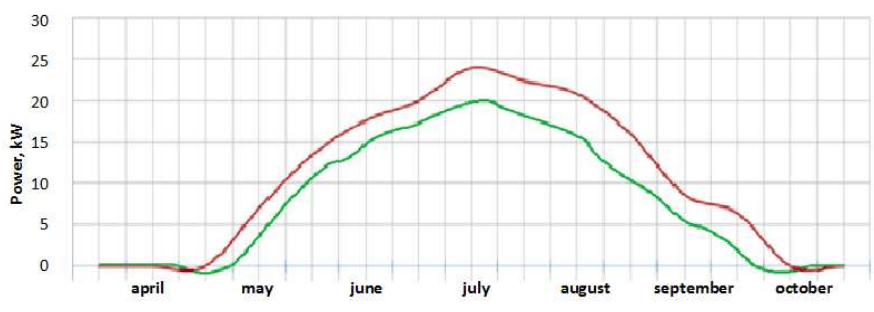

Fig. 10. Instantaneous power distribution of hot water supply solar plant before and after introduction of the developed control method.

It should be noted that flat solar collectors without selective coating were used for the studied system, which means that when some other types of the collectors are used, higher thermal performance of the solar plant might be obtained.

\section{CONCLUSION}

Thus, implementing the control system with the price ranging from 150 to 200 thousand rubles, a high level of energy efficiency of solar plant is achieved. Taking into account the peculiarities of the geographical location of Russia, this solution could be the determining factor for success achievement. [1].

It is not the deficit of solar radiation which is considered as the main obstacle for the application of solar water heating systems in the areas with temperate continental climate. It is rather their low operating efficiency when a standard approach of control is used, as well as high initial cost; although certain design solutions reduce the cost of equipment and space needed for this equipment. Nevertheless, the adaptive control used to monitor heat transfer process allows achieving an operating efficiency sufficient for the seasonal use of the solar plant as the main source of hot water with the payback period much shorter than its operating life.

\section{SUMMARY}

1. Traditional methods applied to provide control for solar plants in a temperate continental climate is not energy efficient because of the poor quality of heat exchange process control between the loops.

2. Mathematical modeling has shown that the water heating plant is rather inertial unit (the time constants are tens of minutes); for this reason the process of control is quite specific.

3. Application of indirect compensation of the external influences when designing the control system simplifies its structure and reduces the requirements set for the control devices, which positively affects the material component in the implementation of this approach.

4. Practical application of the adaptive step-by-step control mechanism made it possible to increase the performance of the plant when it is actively operated at relatively low modification costs. These outcomes prove the ideas of the causes of low energy efficiency of solar plants under conditions of a temperate continental climate and the effectiveness of the developed control methods.

\section{References}

[1] A.V. Belousov, S.N. Glagolev, Y.A. Koshlich, A.G. Grebenik, "The analysis of exploitation possibility of thermal solar plants depending on specific of climate conditions of territory", Life Sci J, vol. 11(12s), pp.1018-1023, November 2014.

[2] A.S. Steklenev, O.N. Tolmachev, "Problems and prospects of using alternative energy sources in Russian Federation", The youth science and technology bulletin, vol. 3, pp. 21-26, 2014.

[3] Ch. Yana, Sh. Wanga, Zh. Mab, W. Shic, "A simplified method for optimal design of solar water heating systems based on life-cycle energy analysis", Renewable Energy, vol. 74, pp. 271-278, 2015.

[4] J. Zhu, H.Y. Chan, S.B. Riffat, "Review of passive solar heating and cooling technologies", Renewable and Sustainable Energy Reviews, vol. 14, pp. 781-789, 2010.

[5] D.H. Archer, M. Qua, H. Yinb, "A solar thermal cooling and heating system for a building: Experimental and model based performance analysis and design”, Solar Energy, vol. 84, pp. 166-182, 2010.

[6] R. Goic, M. Thirugnanasambandama, S. Iniyanb, "A review of solar thermal technologies", Renewable and Sustainable Energy Reviews, vol. 14, pp. 312-322, 2010.

[7] V.A. Butuzov, "Solar heating in Russia: status and regional characteristics", International Scientific Journal for Alternative Energy and Ecology, vol. 7, pp. 75-90, 2009.

[8] A.A. Gaponov, I.V. Turin, "Energy saving control of additional energy source in two-circuit solar heating systems", Bulletin of energy efficiency, vol. 1, pp. 33-38, 2015.

[9] A.P. Kopelovich, The engineering solving methods of regulators [Inzhenernye metody rascheta pri vybore avtomaticheskih regulatorov]. Metallurgizdat, 1960.

[10] A. Belousov, Yu. Koshlich, S. Glagolev, A. Grebenik, "Optimal adaptive control of solar hot water supply system", SGEM Conference Proceeding 2015 BOOK $4-$ ENERGY AND CLEAN TECHNOLOGIES, vol. 1, pp. 361-368, June 2015 [15th International Multidisciplinary Scientific GeoConference 2015, p.568, 2015].

[11] S. Sanaye, A. Sarrafi, "Optimization of combined cooling, heating and power generation by a solar system", Renewable Energy, vol. 80, pp. 699-712, 2012.

[12] A.W. Beckman, J.A. Duffie, Solar Engineering of Thermal Processes, $4^{\text {th }}$ ed. John Wiley \& Sons, Inc., 2013. 